\title{
Metamorphosis of a sesarmid river crab, Armases roberti: stimulation by adult odours versus inhibition by salinity stress
}

\author{
KLAUS ANGER ${ }^{1}$, GABRIELA TORRES $^{1,2}$, \& LUIS GIMÉNEZ ${ }^{1,3}$ \\ ${ }^{1}$ Biologische Anstalt Helgoland, Foundation Alfred Wegener Institute for Polar and Marine \\ Research, 27498 Helgoland, Germany, ${ }^{2}$ AG Zoosystematik and Morphologie, Carl von Ossietzky \\ Universität Oldenburg, 26129 Oldenburg, Germany, and ${ }^{3}$ Sección Oceanología, Facultad de \\ Ciencias, Universidad de la República, 11400 Montevideo, Uruguay
}

(Received 1 fune 2006; in final form 20 August 2006)

\begin{abstract}
In an experimental laboratory study with the megalopa stage of Armases roberti, a freshwaterinhabiting species of crab from the Caribbean region, we evaluated the combined, potentially antagonistic effects of odours from conspecific adults and of stepwise salinity reductions (simulating upstream migration, reaching within 1 week conditions of $2 \%$ or freshwater). Neither of these treatments affected the rate of survival, but the duration of development to metamorphosis was significantly (by about 25\%) shortened, when odours from conspecific adult crabs were present, regardless of the salinity conditions. Our results indicate that the metamorphosis-stimulating effect of chemical cues from an adult population of $A$. roberti is far stronger than the potentially retarding effect of increasing hypoosmotic stress. This suggests that the final phase of larval development, including the processes of settlement and metamorphosis, occurs in this species in freshwater habitats, where conspecific populations live.
\end{abstract}

Keywords: Crustaceans, larval biology, metamorphosis, ontogenetic migrations, salinity tolerance, chemical cues, recruitment

\section{Introduction}

Numerous species of estuarine and freshwater-inhabiting animals pass through a physiologically vulnerable larval phase, which cannot successfully be completed within the brackish or limnic environments where the adults live. The early life history stages must therefore be "exported" to more favourable regions, where the salinities are, on average, 
higher and more stable (Anger 2001, 2003). This spatial transfer of the larval phase can either be achieved by reproductive migrations of the ovigerous females towards the sea (e.g. Forward et al. 2005; Rudnick et al. 2005), or hatching may occur within the adult habitat, followed by a rapid passive downstream transport of the first planktonic larval stage, utilizing the outflowing surface currents or tidal mechanisms of downstream transport (for recent review, see Queiroga and Blanton 2005).

Although such "export strategies" (Strathmann 1982) allow for successful larval development in the lower (more saline) parts of estuaries or in coastal marine regions, it remains generally an open question, which life history stage attains the physiological competence for reimmigration and recruitment to adult populations. Upstream migrations imply the crossing of strong salinity gradients, requiring tolerance of an increasing hypoosmotic stress. It is assumed that the reimmigration into estuaries or rivers begins in some cases during the final larval stage, the decapodid or megalopa (e.g. Forward et al. 2003), while other species may attain this competence only in subsequent benthic juvenile stages (for references, see Charmantier 1998; Anger 2001, 2003). The question of the ontogenetic timing of the return to brackish or freshwater habitats can be resolved either with studies of larval distribution in the field or with an experimental approach, testing late larval or early juvenile stages in the laboratory for their salinity tolerance. The latter approach was chosen in the present study.

Besides physical stress occurring during ontogenetic migrations, benthic species with complex life cycles must face another problem: the time spent as larvae in the plankton confers several risks of mortality due to pelagic predation and other adverse factors (for review, see Morgan 1995). This selection pressure should limit the duration of the planktonic larval phase, and hence, also the duration and extent of ontogenetic migrations. In some species, this is achieved through megalopal responses to chemical cues that originate from habitats of the conspecific adults (including adult odours), accelerating the development to metamorphosis (Forward et al. 2001; Gebauer et al. 2003). On the other hand, physiological constraints imposed by weakly developed capabilities of osmoregulation may limit the possible rate of larval upstream migration through salinity gradients (Charmantier 1998; Anger 2003). This implies a trade-off between various risks of mortality during the larval phase.

In the present study, we used Armases roberti (H. Milne Edwards), a little known, freshwater-inhabiting and semiterrestrial crab from the Caribbean island of Jamaica to study the potentially antagonistic effects of metamorphosis-stimulating chemical cues from conspecific adults, in combination with an increasing hypoosmotic stress. Adult populations of this "river crab" live in freshwater up to ca $10 \mathrm{~km}$ from the sea (Chace and Hobbs 1969; Abele 1992; Diesel and Schuh 1998). Previous laboratory observations (Diesel and Schuh 1998) showed that the zoeae of this species hatched in freshwater, where they could survive for up to ca 2 days. However, when the zoeae were continually exposed to reduced salinities below 15\%, they revealed a stenohaline response, which would not allow for larval development near the limnic habitats of conspecific adult populations. In conclusion, this species must follow an export strategy. The experimental data by Diesel and Schuh (1998) suggested an optimal development at about 25\% rather than under fully marine or hypersaline conditions. On the one hand, this might indicate that zoeal development normally takes place in lower estuarine zones, where moderately reduced salinities prevail. On the other hand, a wide geographic distribution of this species throughout the Caribbean region (Abele 1992) indicates that there must also be at least occasional larval transport with fully marine coastal and oceanic water currents. 
These life history patterns of $A$. roberti raise the question, in which ontogenetic stage its reimmigration into brackish and freshwater habitats becomes physiologically possible, and how those recruitment migrations are triggered. A recent study by Torres et al. (2006) showed that the megalopa stage of this species is very euryhaline and probably capable of immigrating into estuaries and rivers. During their presumable upstream migration, however, the megalopae are not only increasingly exposed to reduced salinities, but also to attracting chemical cues from the riverine habitats of conspecific adults. Such cues have been shown to stimulate metamorphosis in several species of sesarmid crabs (for review, see Gebauer et al. 2003), but it has remained unknown if this response occurs also in the megalopa stage of $A$. roberti. We tested this in the present study, evaluating combined (theoretically antagonistic) effects of an exposure to adult odours and reduced salinities.

\section{Materials and methods}

\section{Habitat characteristics}

As only little is known about the ecology of $A$. roberti (Chace and Hobbs 1969; Abele 1992), we provide here a short description of presumably typical habitats, where we collected these crabs in March 2003 and 2004, and in April 2006. Most material originated from the lower Rio Bueno River, near the town of Rio Bueno, northern Jamaica (Figure 1A,B). On 11 April 2006, the following water characteristics were measured at the collection site, using a

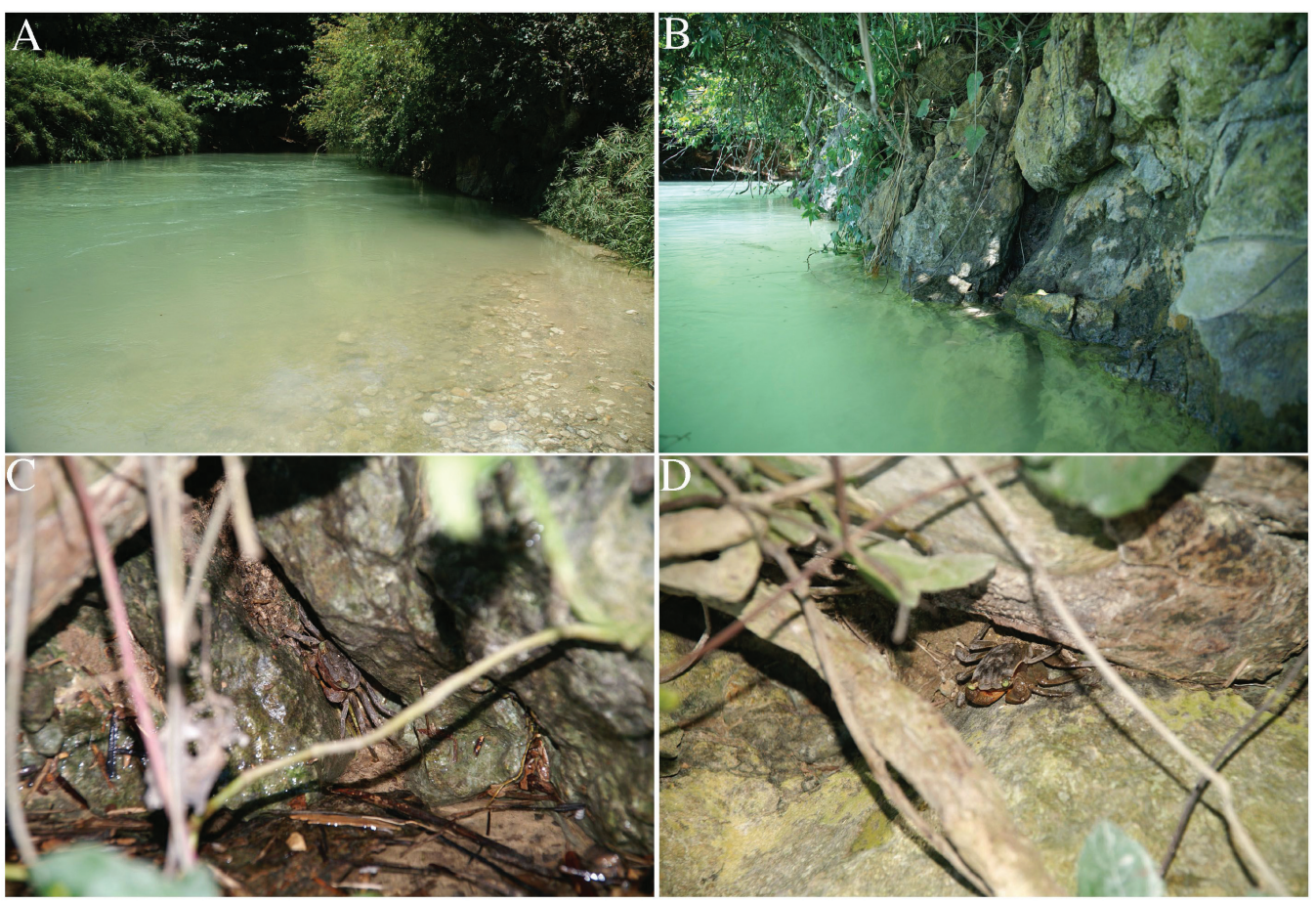

Figure 1. Armases roberti, typical habitat. (A) Rio Bueno River near the town of Rio Bueno, northern Jamaica; (B) same site, river bank with typical habitats (shaded rock crevices, vegetation, roots of trees and other plants; above the water level); (C) male; (D) female. 
"Combo pH and EC" apparatus (Hanna Instruments, Kehl, Germany): temperature $23.8^{\circ} \mathrm{C}$; conductivity $0.38 \mathrm{mS} \mathrm{cm}^{-1}$; total dissolved matter $0.19 \%$ (or ppt); $\mathrm{pH} 8.10$. The flow velocity (roughly estimated with plastic floaters and a graded measuring rod) was ca $100 \mathrm{~cm} \mathrm{~s}^{-1}$. According to frequent previous observations, these conditions are typical for this site, at least during spring. Both juvenile crabs (minimum ca $3 \mathrm{~mm}$ carapace size) and adults (above $1 \mathrm{~cm}$ ) were observed on the riverbanks above the water level, mostly in or near rock crevices, especially on shady places under terrestrial vegetation (Figure 1C,D). When crabs were disturbed, they jumped into the water, but they soon crawled up again, showing semiterrestrial rather than aquatic behaviour. Additional crabs of this species were collected from the Dunns River Falls (ca $45 \mathrm{~km}$ east of Rio Bueno), where similar water characteristics were measured: temperature $24.9^{\circ} \mathrm{C}$; conductivity $0.29 \mathrm{mS} \mathrm{cm}^{-1}$; total dissolved matter $0.14 \%$; pH 8.48; flow velocity ca $120 \mathrm{~cm} \mathrm{~s}^{-1}$.

\section{Obtaining and rearing of larvae}

Ovigerous crabs were transported to the Helgoland Marine Biological Station (Germany), and thereafter maintained in aquaria with freshwater $\left(0.41 \mathrm{mS} \mathrm{cm}^{-1}\right.$; total dissolved matter $0.20 \%$ o $\mathrm{pH} 8.00)$, kept under constant temperature $\left(24^{\circ} \mathrm{C}\right)$ and a $12: 12 \mathrm{~h}$ photoperiod. Food (frozen isopods, Idotea sp.) and water were changed daily. After hatching in freshwater, zoeae from one female (originating from the Rio Bueno River) were mass-reared in bowls with $400 \mathrm{~mL}$ (initial density 50 zoeae per bowl) at the same conditions of temperature and light, but at a salinity of $25 \%$, until they reached metamorphosis to the megalopa stage. Water was changed daily, and the larvae were fed ad libitum with freshly hatched brine shrimp (Artemia franciscana) nauplii (ca 10 per $\mathrm{mL}$ ).

Different experimental salinities were obtained by diluting filtered seawater from the North Sea (ca $1 \mu \mathrm{m}$ filter pore size; 32\%o) with appropriate quantities of freshwater. For experiments with an exposure to odours from conspecific adults, salinities were adjusted by diluting seawater with filtered freshwater taken from aquaria in which adult crabs had been placed for $48 \mathrm{~h}$ previous to the experiment (one adult male and one female crab per $4 \mathrm{~L}$ freshwater). The adults (ca $2 \mathrm{~cm}$ carapace width) were not fed during this period in order to avoid potentially confounding effects of mixed odours originating from the adult crabs and their food.

\section{Experimental design and statistical analysis}

Megalopae were divided into four groups (factorial design) to test for effects of (a) the presence (denoted with + in Figure 3 ) or absence $(-$ ) of chemical cues (conspecific adult odours); (b) of two different speeds of stepwise salinity decrease (from hereon referred to as "fast" and "slow", respectively; or F and S, Figure 3). All experiments began with an immediate postmoult transfer of megalopae from 25 to $15 \%$. In $\mathrm{S}$ treatments, salinity was thereafter reduced every 2 days, reaching a condition of $2 \%$ after 6 days, while $\mathrm{F}$ treatments implied daily reductions, reaching freshwater conditions after 6 days. In all treatments, the salinity reached after 6 days remained constant until the megalopae either died or metamorphosed to juvenile crabs. In each of these four treatments, the megalopae were group-reared in 11-14 replicate bowls (a few replicates were accidentally lost), with initially 20 individuals per replicate (i.e. 960 megalopae in total), and a piece of nylon gauze provided as a substrate. Conditions of water change, feeding, temperature and light were the same as for zoeal rearing. Additionally, we recorded in daily intervals the occurrence of moults or deaths. The duration of megalopa development (or time to metamorphosis) was defined as 
the time span between the moult from the zoea IV to the megalopa and that between the megalopa and the first juvenile crab stage.

Data on survival and duration of development were analysed with two-way ANOVAs (Zar 1998) with factors "chemical cues" (two treatments, with or without adult water) and "salinity decrease" (two treatments, fast or slow).

\section{Photographs}

Photographs of adult crabs and their habitat were taken with a Konica Minolta Dynax 7D (6.1 Megapixel) digital camera. Micrographs of larvae and juveniles were taken with an Olympus Color View Imaging System attached to a SZX12 stereo microscope.

\section{Results and discussion}

\section{Larval development and chromatophore patterns}

While a detailed morphological description of all larval stages and of the first juvenile crab instar of $A$. roberti will be published elsewhere, the present article provides a preliminary account of the pattern of larval development in this species. Consistent with a previous study (Diesel and Schuh 1998), development from hatching to metamorphosis comprised, in our experiments, invariably four zoeal stages (at $24^{\circ} \mathrm{C}$ lasting 3-4 days each) and a megalopa (Figure 2). The latter stage was reached, on average, 15 days after hatching. The duration of development through the megalopa stage varied from 10-18 days, depending on the rearing conditions (see below).

The larvae showed a characteristic pigmentation, which may become useful as an additional criterion for their identification in plankton samples, as soon as comparable descriptions are provided for other species of Armases co-occurring with $A$. roberti in the same region (cf Abele 1992). From hatching, the zoeae showed on the second and third pleonal body segments two pairs of large white to bright yellow ventro-lateral chromatophores (Figure $1 \mathrm{~A}-\mathrm{C}$ ). They were present throughout the zoeal stages I-III, but disappeared in the zoeal stage IV (Figure 1D). Moreover, all zoeal stages showed on all pleonal somites as well as on the carapace and maxillipedes scatters of small orange chromatophores. The same type of chromatophores also occurred in the megalopa stage, especially latero-ventrally and dorsally on the carapace and, although less, dorsally on all pleonal somites. A third type of chromatophores, intermediate in size and dark red or brown in colour, was observed dorso-laterally and distally on the carapace, and on the pleonal somites of the zoeal stages, increasing during development in number and size. In the megalopa, pairs of brown chromatophores occurred ventrally on all pleonal somites, near the feeding appendages, and dorsally on and between the eye stalks, as well as in the anteriomedian carapace region (Figure 2E).

The first-stage juvenile crabs are characterized by numerous small bright yellow chromatophores on the dorsal sides of the carapace and of the eye stalks (Figure 2F). The same type of chromatophores also occurs on all walking legs and on the chelae, but with a slightly lower density. In addition, the pereiopods also show orange chromatophores, which are slightly larger and occur in higher numbers. Four large brown, strongly ramified chromatophores are distributed along the median line of the dorsal carapace surface. The same type of chromatophores is also scattered over the ventral carapace surface and on the ventrally bent pleon (not visible in Figure $2 \mathrm{~F}$ ). 


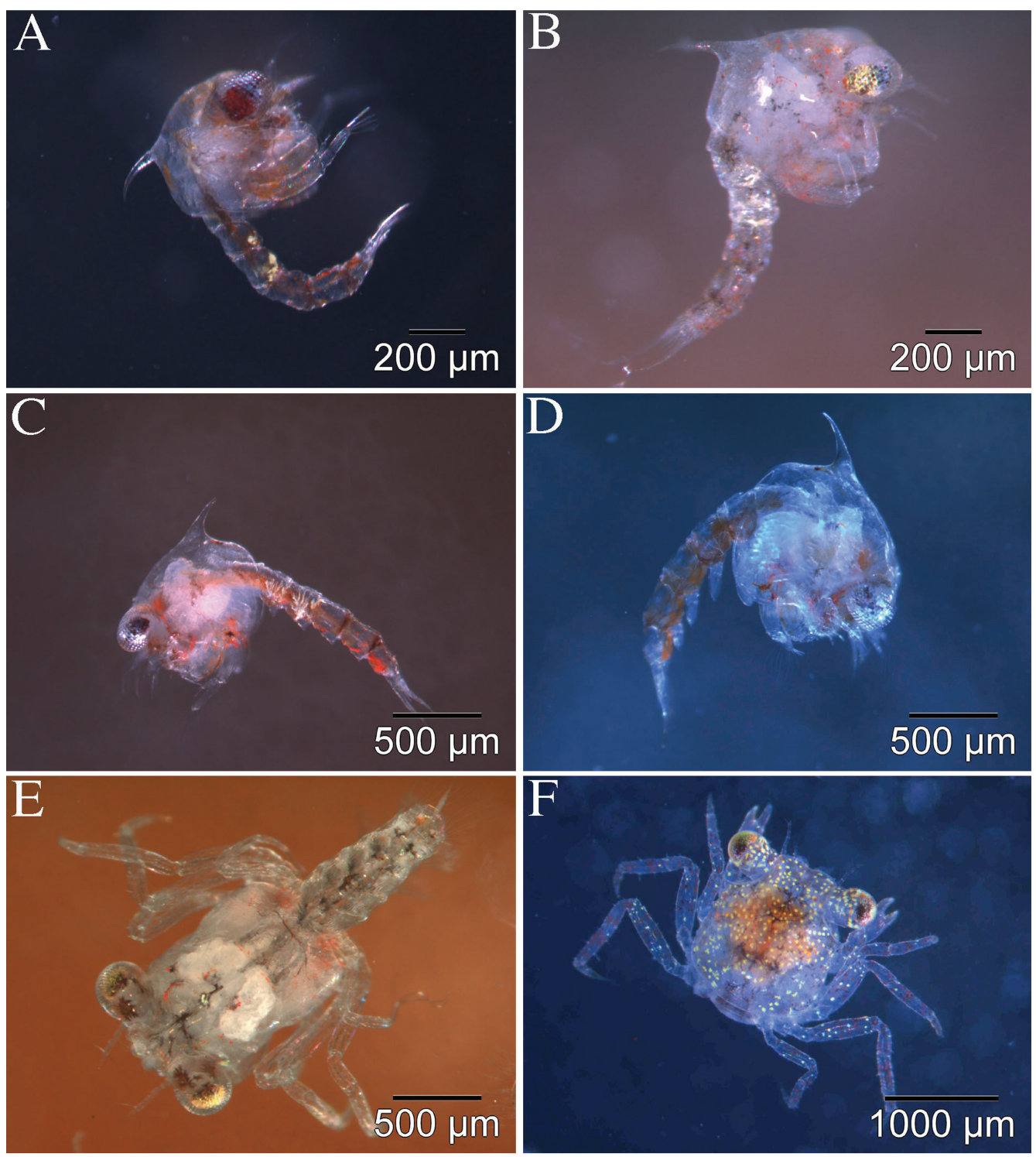

Figure 2. Armases roberti, development from larval hatching through metamorphosis. (A)-(D), zoeal stages I-IV; (E) megalopa; (F) first juvenile crab stage.

\section{Effects of salinity on the megalopa stage}

The rate of survival through the megalopa stage was generally high (70-76\%) and neither significantly affected by the speed of salinity reduction (slow vs. fast; cf Figure 3), nor by the presence or absence of chemical cues from conspecific adults (Table I; Figure 4A). Our experiments proved that the megalopa stage of $A$. roberti is physiologically capable of acclimating rapidly (within 6 days) to dramatically decreasing salinities. This acclimation allows not only continued survival (for another 6-8 days) but also successful metamorphosis to the first juvenile crab stage under oligohaline or freshwater conditions $(0.18-2.0 \%$ ). 
Treatment:

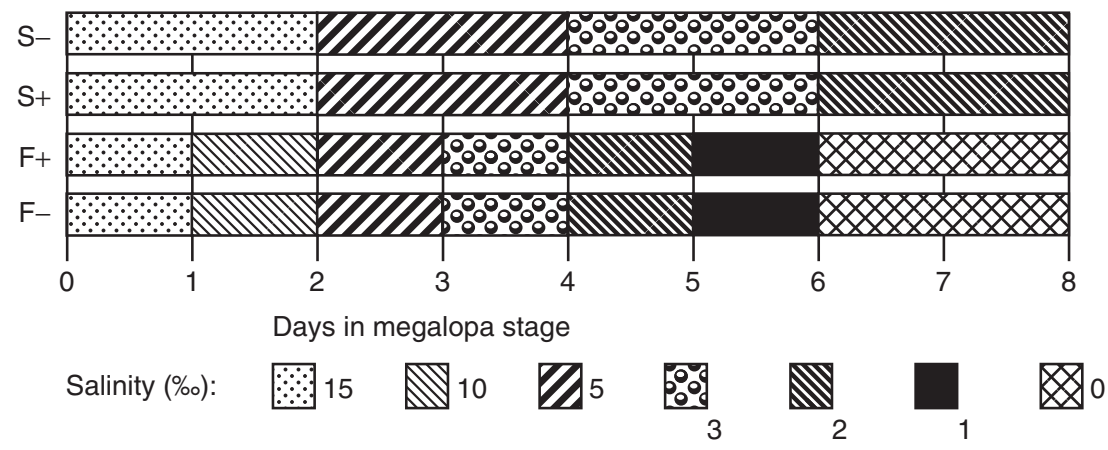

Figure 3. Experimental design. Treatments with slow $(S)$ or fast $(F)$ reductions of salinity during the first 6 days of megalopal development, in combination with $(+)$ or without $(-$ ) chemical cues (odours from conspecific adult crabs).

Table I. Two-way ANOVA: effects of salinity reductions (fast vs. slow; cf Figure 3) and of the presence or absence of chemical cues from conspecific adults on survival and duration of development through the megalopa stage of $A$. roberti.

\begin{tabular}{|c|c|c|c|c|}
\hline Factor & $\mathrm{df}$ & MS & $F$ & $p$ \\
\hline \multicolumn{5}{|l|}{ Survival } \\
\hline Salinity reduction & 1 & 0.000002 & 0.0001 & 0.99 \\
\hline Cues & 1 & 0.000066 & 0.0052 & 0.94 \\
\hline Salinity reduction $\times$ cues & 1 & 0.036317 & 2.8515 & 0.09 \\
\hline Error & 44 & 0.012736 & & \\
\hline \multicolumn{5}{|l|}{ Duration of development } \\
\hline Salinity reduction & 1 & 0.002 & 0.001 & 0.98 \\
\hline Cues & 1 & 130.984 & 61.267 & $<0.0001$ \\
\hline Salinity reduction $\times$ cues & 1 & 4.617 & 2.160 & 0.15 \\
\hline Error & 44 & 2.138 & & \\
\hline
\end{tabular}

A recent study (Torres et al. 2006) showed that similarly low salinities (0-3\%o) were not tolerated without previous acclimation. The limit for megalopal survival under continued exposure to low salinities was observed at 5\%, although this treatment caused significantly enhanced mortality and a developmental delay. The euryhalinity and the remarkable adaptability to rapidly decreasing osmotic pressures in the megalopa stage is a prerequisite for upstream migration and recruitment in brackish and limnic zones.

Since the tolerance of reduced salinities is based upon the expression of the physiological function of hyperosmoregulation (Charmantier 1998; Anger 2003), our findings suggest that the megalopa of $A$. roberti enhances this function gradually during the course of its moulting cycle. This capability requires an appearance of ion-transporting cells (ionocytes) and regulating tissues, which may be located in the larval brachiostegites and/or the developing gills (see Cieluch et al. 2004, 2005; and earlier references therein). The formation of specialized ion-transporting tissues follows a developmental programme, which might be stimulated and accelerated by an increasing hypoosmotic challenge by stepwise reductions of salinity. This hypothesis is supported by a study on another grapsoid crab, Chasmagnathus granulata, where a significant enhancement of early larval hyperosmoregulation occurred after previous embryonic acclimation to a reduced salinity 
(Charmantier et al. 2002). Future investigations will have to identify the physiological and structural basis of the unusually great salinity tolerance of the megalopa of $A$. roberti, including the process of gradual acclimation and presumably accelerated appearance of ionocytes.

\section{Effects of adult odours on the megalopa stage}

During their migration into rivers, the megalopae of $A$. roberti are also exposed to increasing concentrations of chemical cues originating from upstream habitats, where the adults live. Our experiments showed that such cues, namely odours released by conspecific adult crabs, had a significant metamorphosis-stimulating effect, reducing the duration of the final larval stage by about $25 \%$ (Figure $4 \mathrm{~B}$; Table I). Remarkably, this effect occurred regardless of the salinity conditions. In conclusion, our study suggests that metamorphosis of $A$. roberti is, also in the natural estuarine and riverine habitats of this species, triggered by chemical cues indicating the presence of conspecific adult populations further upstream, while rapidly
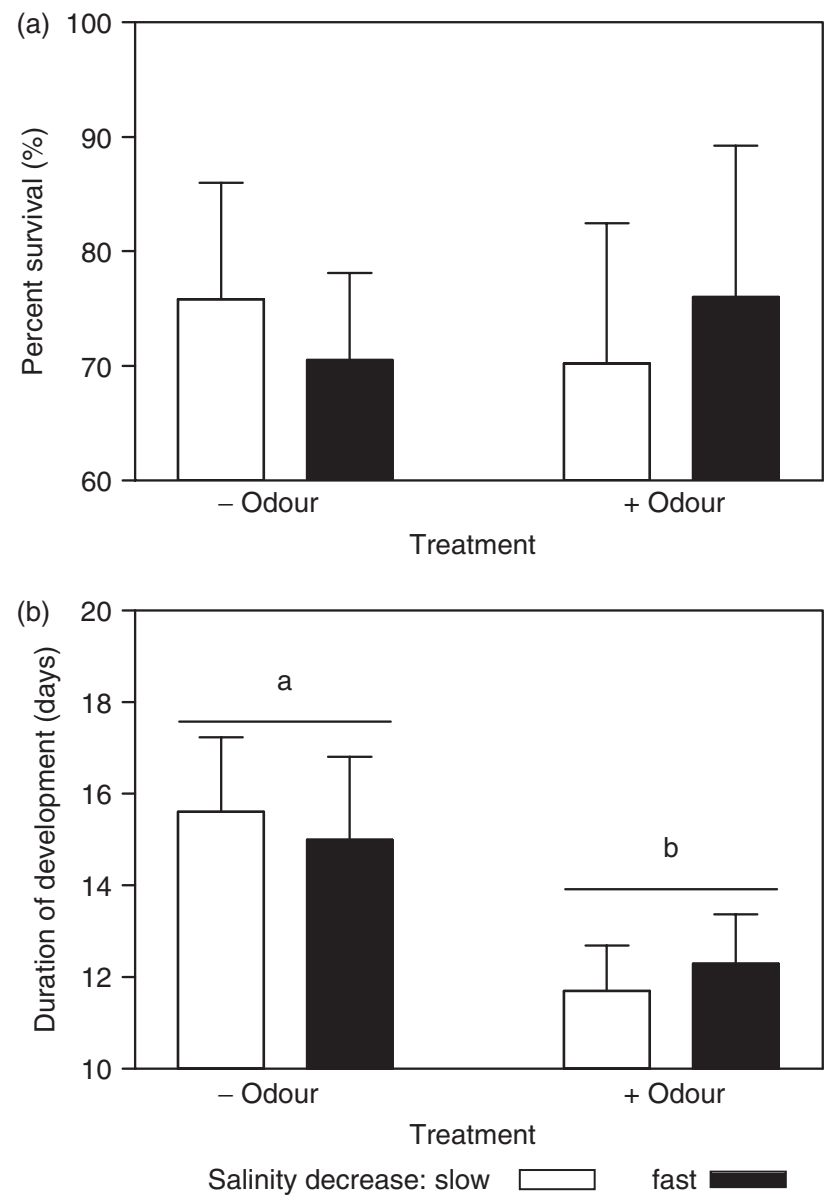

Figure 4. Armases roberti. (A) Survival; (B) duration of development through the megalopa stage to metamorphosis, during exposure to slow or fast reductions of salinity, in combination with $(+)$ or without ( - ) chemical cues (odours from conspecific adult crabs; for experimental design, cf Figure 3). 
decreasing salinities (from $25 \%$ o to freshwater within only 6 days) seem to have hardly any limiting effect on megalopal upstream migration.

In the two treatments without adult odours, the average durations of megalopal development were consistently longer than observed in a previous study (Torres et al. 2006). The difference (ca 12 vs. 15 days) cannot be explained by variation in salinities, chemical cues or other external factors, but reflects intraspecific variability among hatches reared at similar conditions, probably due to genetic and/or other maternal factors. Significant differences between larvae produced by different females and reared under similar conditions have been observed in most larval features including survival, duration of development, biomass, growth rate, and in some species even in the number of larval stages (for references, see Anger 2001, Giménez and Anger 2003). Likewise, the extent of the metamorphosis-accelerating response to adult odours has been shown to reveal significant intraspecific variability (Gebauer et al. 2005). This indicates that comparisons between results from different studies conducted with larvae from different conspecific females must be made with caution.

Chemical triggers from adult populations should not only lead megalopal reimmigration into the "right" direction. Additionally, the acceleration of megalopal development to metamorphosis should mitigate also potentially negative effects of hypoosmotic stress, because the subsequent benthic juvenile crab stages are, compared to the megalopae, osmotically better protected by a thicker and less permeable cuticle. Moreover, young crabs have generally stronger capabilities of hyperosmoregulation (Charmantier 1998; Anger 2003). As a consequence, the early juveniles may continue the upstream migration into rivers, without suffering from osmotic stress. The initial and decisive steps of recruitment, however, are in $A$. roberti most probably made already during the megalopa stage. Its euryhalinity and physiological adaptability to rapidly decreasing salinities, together with its metamorphosis-accelerating response to odours from conspecific adults, may be considered crucial life history adaptations that permitted the invasion of freshwater environments during the evolution of this species of crab.

\section{Acknowledgements}

We thank U. Nettelmann and K. Boos for help in the experiments and Dr A. Malzahn who helped using the micrograph imaging software. G. T. acknowledges the Deutscher Akademischer Austausch Dienst, DAAD (Bonn, Germany), for funding this study as a part of her doctoral dissertation, and LG the Alexander-von-Humboldt Foundation (Bonn, Germany) for a postdoctoral research grant. The experiments comply with the current German animal and manipulation laws.

\section{References}

Abele LG. 1992. A review of the grapsid crab genus Sesarma (Crustacea: Decapoda: Grapsidae) in America, with the description of a new genus. Smithsonian Contr. Zool. 527:1-60.

Anger K. 2001. The biology of decapod crustacean larvae, crustacean issues. Vol. 14. Lisse, The Netherlands: A.A. Balkema.

Anger K. 2003. Salinity as a key parameter in the larval biology of decapod crustaceans. Invert. Reprod. Develop. 43:29-45.

Chace FA, Hobbs HH. 1969. The freshwater and terrestrial decapod crustaceans of the West Indies with special reference to Dominica. Bulletin of National Museum USA 292:1-298. 
Charmantier G. 1998. Ontogeny of osmoregulation in crustaceans: a review. Invert. Reprod. Develop. 33:177-190.

Charmantier G, Giménez L, Charmantier-Daures M, Anger K. 2002. Ontogeny of osmoregulation, physiological plasticity, and larval export strategy in the grapsid crab Chasmagnathus granulata (Crustacea, Decapoda). Mar. Ecol. Prog. Ser. 229:185-194.

Cieluch U, Anger K, Aujoulat F, Buchholz F, Charmantier-Daures M, Charmantier G. 2004. Ontogeny of osmoregulatory structures and functions in the green crab, Carcinus maenas (Crustacea, Decapoda). J. Exp. Biol. 207:325-336.

Cieluch U, Charmantier G, Grousset E, Charmantier-Daures M, Anger K. 2005. Osmoregulation, immunolocalization of $\mathrm{Na}^{+} / \mathrm{K}^{+}$-ATPase, and ultrastructure of branchial epithelia in the developing brown shrimp, Crangon crangon (Decapoda, Caridea). Physiol. Biochem. Zool. 78:1017-1025.

Diesel R, Schuh M. 1998. Effects of salinity and starvation on larval development of the crabs Armases ricordi and A. roberti (Decapoda: Grapsidae) from Jamaica, with notes on the biology and ecology of adults. J. Crustacean Biol. 18:423-436.

Forward RB, Cohen JH, Darnell MZ, Saal A. 2005. The circatidal rhythm in vertical swimming of female blue crabs, Callinectes sapidus, during their spawning migration: A reconsideration. J. Shellfish Res. 24:587-590.

Forward RB, Tankersley RA, Rittschof D. 2001. Cues for metamorphosis of brachyuran crabs: an overview. Am. Zool. 41:1108-1122.

Forward RB, Tankersley RA, Smith KA, Welch JM. 2003. Effects of chemical cues on orientation of blue crab, Callinectes sapidus, megalopae in flow: Implications for location of nursery areas. Mar. Biol. 142:747-756.

Gebauer P, Paschke KA, Anger K. 2003. Delayed metamorphosis in Decapod Crustaceans: evidence and consequences. Rev. Chilena Hist. Nat. 76:169-175.

Gebauer P, Paschke KA, Anger K. 2005. Temporal window of receptivity and intraspecific variability in the responsiveness to metamorphosis-stimulating cues in the megalopa of a semi-terrestrial crab, Sesarma curacaoense. Invert. Reprod. Develop. 47:39-50.

Giménez L, Anger K. 2003. Larval performance in an estuarine crab, Chasmagnathus granulata, is a consequence of both larval and embryonic experience. Mar. Ecol. Prog. Ser. 249:251-264.

Morgan SG. 1995. Life and death in the plankton: larval mortality and adaptation. In: McEdward LR, editor. Ecology of Marine Invertebrate Larvae. Boca Raton, FL: CRC Press. pp 279-321.

Queiroga H, Blanton J. 2005. Interactions between behaviour and physical forcing in the control of horizontal transport of decapod crustacean larvae. Adv. Mar. Biol. 47:107-214.

Rudnick D, Veldhuizen T, Tullis R, Culver C, Hieb K, Tsukimura B. 2005. A life history model for the San Francisco estuary population of the Chinese mitten crab, Eriocheir sinensis (Decapoda: Grapsoidea). Biol. Inv. 7:333-350.

Strathmann RR. 1982. Selection for retention or export of larvae in estuaries. In: Kennedy VS, editor. Estuarine Comparisons. San Diego: Academic Press. pp 521-535.

Torres G, Anger K, Giménez L. 2006. Effects of reduced salinities on metamorphosis of a freshwater-tolerant sesarmid crab, Armases roberti: is upstream migration in the megalopa stage constrained by increasing osmotic stress? J. Exp. Mar. Biol. Ecol. 338:134-139.

Zar J. (1998). Biostatistical analysis. 4th ed. Upper Saddle River, New Jersey, USA: Prentice Hall. 